\title{
Interactive comment on "Anthropogenic climate change and glacier lake outburst flood risk: local and global drivers and responsibilities for the case of Lake Palcacocha, Peru" by Christian Huggel et al.
}

Christian Huggel et al.

christian.huggel@geo.uzh.ch

Received and published: 5 June 2020

Author response: We would like to thank the author team of this comment for their engagement with this study and the very valuable comments they provide. To some extent similar as in the case of the comment by Will Frank we think that we're departing from somewhat different perspectives. In our paper we are primarily interested in how risk evolves over time and what the driving forces are from local to global, and what this means in terms of responsibilities. In this comment there is a stronger push towards the causality issue, which is also important, and we do touch upon it to some extent

Printer-friendly version

Discussion paper 
as well in our paper, but not as a central aspect. Having said this, we're nevertheless glad that you bring up the issue of glacier (and glacier lake) attribution to anthropogenic climate change. Unfortunately, we're confronted with a scarcity of research on climateglacier attribution in general, and in particular for the tropical Andes region, by far the largest glacierized region in the tropics. We built our attribution analysis (section 3 ) on existing literature from climatic change in the region to climate-glacier studies. We also agree that we should be more careful in referring to the Marzeion et al. (2014) paper and we clearly acknowledge the problems as you outline. We may add to this that one of the underlying problems of this study (and others as well) is the inadequate climate data that is used, with insufficient quality, or temporal and spatial coverage/resolution, a limitation that many climate datasets for this region share due to scarce climatological on the ground measurements and complex topography and climatology in the high Andes. While we don't see the space and scope in our paper to go into substantial detail about climate-glacier change attribution, we revised section 3 to accommodate the concerns that are pointed out here. Specifically, we are happy to take on board the new evidence available from Stuart-Smith et al. (in review). Based on this comment and the previous one by Will Frank, we revised the following text sections: lines 191194 (putting the Marzeion et al. 2014 study in perspective, with more evidence by Stuart-Smith et al. in review); lines 224-228: we revised the statement that GLOF hazard attribution to anthropogenic climate change can only be qualitative and refere here to the Stuart-Smith et al study.

Reference: Stuart-Smith, R.F., Roe, G.H., Li, S., Allen, M.R., 2020. Anthropogenic contribution to the retreat of Palcaraju glacier (Cordillera Blanca, Peru) and glacial lake outburst flood risk. Nat. Geosci. in review

Furthermore, based on the comments by Will Frank and Stuart-Smith et al. we also recognize the need for further clarification of the type of responsibilities we're addressing in our study. We do not focus on any legal responsibility. We added a clarification at the beginning of section 7 (Implications for responsibility and justice) where we first

Interactive

comment

Printer-friendly version

Discussion paper 
outline the four aspects when assigning responsibilities. We specifically add that this conceptualization of responsibility encompasses aspects of legal liability, explaining the link between the subject of responsibility and the object of responsibility, but clarify that our understanding of responsibility goes beyond the legal and liability framing. This also addresses the concerns of the two comments that the social, economic and institutional drivers of risk are irrelevant for the court case or decision. We basically agree on this (but the court decision will give us more precision in this respect) but for our concept of responsibility these risk drivers are clearly relevant.

Interactive comment on Nat. Hazards Earth Syst. Sci. Discuss., https://doi.org/10.5194/nhess2020-44, 2020. 